\title{
Predictive and criterion validity of the Cervantes-SF menopause quality of life questionnaire
}

\author{
Pluvio J. Coronado MD PhD', Manuel Monroy PhD', María Fasero MD PhD ${ }^{3}$, Laura \\ Baquedano MD PhD ${ }^{4}$, Nicolás Mendoza MD PhD ${ }^{5}$, Plácido Llaneza MD PhD ${ }^{6}$, Javier \\ Rejas $\mathrm{MD}^{7}$, Miguel A. Ruiz $\mathrm{PhD}^{2}$ and the AEEM group for the development of the \\ Cervantes-SF scale.
}

\begin{abstract}
${ }^{1}$ Instituto de Salud de la Mujer, Hospital Clínico San Carlos, IdISSC, Universidad Complutense, Madrid; ${ }^{2}$ Facultad de Psicología, Universidad Autónoma de Madrid, Madrid; ${ }^{3}$ Servicio de Obstetricia y Ginecología, Hospital Sanitas La Zarzuela. Universidad Francisco de Vitoria, Madrid; ${ }^{4}$ Servicio de Obstetricia y Ginecología, Hospital Miguel Servet, Zaragoza; ${ }^{5}$ Departamento de Obstetricia y Ginecología. Facultad de Medicina. Universidad de Granada; ${ }^{6}$ Departamento de Obstetricia y Ginecología. Hospital Central de Asturias. Universidad de Oviedo; ${ }^{7}$ Departamento de Farmacoeconomía e Investigación de Resultados en Salud, Pfizer SLU, Alcobendas, Madrid.
\end{abstract}

The AEEM group responsible for the development of the Cervantes-SF scale is composed of: Pluvio J. Coronado (Hospital Clínico San Carlos, Madrid), Rafael Sánchez-Borrego (Clínica DIATROS, Barcelona), Laura Baquedano (Hospital Universitario Miguel Servet, Zaragoza), Sonia Sánchez (Hospital Sagrado Corazón, Barcelona), Cristina Argudo (Clínica Begoña, Gijón, Asturias), Micaela Fernández-Abellán (Clínica Quirón, Málaga), Silvia González (Gabinete Médico Velázquez, Madrid), Eva Iglesias (Hospital de Valme, Sevilla), Jackie Calleja (Clínica Quirón, Madrid), Jesús Presa (Hospital Clínico de Jaén), Alfonso Duque (Clínica Ruber, Madrid), Fernando Ruiz (Hospital Clínico Universitario, Valencia), Borja Otero (Hospital Universitario de Cruces, Baracaldo, Vizcaya), María Fasero (Hospital Sanitas La Zarzuela, Madrid), Plácido Llaneza (Hospital Universitario Central de Asturias, Gijón, Asturias) and Santiago Palacios (Instituto Palacios de Salud y Medicina de la Mujer, Madrid).

\section{Correspondence:}

Dr. Pluvio Coronado MD, PhD

Instituto de Salud de la Mujer. Hospital Clínico San Carlos

C/ Prof. Martín Lagos, s/n

28040 Madrid, Spain

Tel.: 913303000

e-mail: pcoronadom@gmail.com 


\section{Running title: Validity of the Cervantes-SF menopause scale}

\section{Funding}

This work was promoted and sponsored by the Spanish Menopause Society (SMS). Statistical analyses were conducted by Manuel Monroy and Miguel Ruiz from the Universidad Autónoma de Madrid, funded by a restricted grant from Pfizer, S.L.U. No editorial support was provided except for a review of the English, conducted by Your English Lab.

\section{Conflict of interest}

The AEEM collaborative group for the study of psychometric validation of the Cervantes Short-Form consists of Pluvio J. Coronado, Rafael Sánchez-Borrego, Laura Baquedano, Sonia Sánchez, Cristina Argudo, Micaela Fernández-Abellán, Silvia González, Eva Iglesias, Jackie Calleja, Jesus Presa, Alfonso Duque, Fernando Ruiz, Borja Otero, María Fasero, Plácido Llaneza y Santiago Palacios. Javier Rejas is an employee of Pfizer, S.L.U. Manuel Monroy and Miguel A. Ruiz are professors of statistics and methodology at the Universidad Autónoma de Madrid and received a grant from Pfizer, S.L.U. for the statistical analysis. All other authors declare that they have no conflicts of interests. 


\section{Abstract}

Objectives: To analyze the predictive and criterion-based validity of the Cervantes-SF scale that measures the impact of menopause on Health-Related Quality of Life (HRQoL).

Methods: We recruited a non-institutionalized sample of peri/postmenopausal women aged 40-75 years, who had their last menstrual cycle $12+$ months prior to inclusion in the study of the psychometric validity of the Cervantes-SF scale. Predictive validity was supported by the explanatory capacity of various health outcome measures administered concomitantly (years of disability-free healthy life expectancy, work productivity and impact on daily activities, economic impact arising from loss of work productivity, hours of undisturbed sleep each day, and the utilization of healthcare facilities), whilst criterion validity was measured by the probability of identifying a moderate to severe vasomotor or genital syndrome requiring specific treatment.

Results: The initial sample included 317 peri/postmenopausal women with a mean age of 55.7 years (SD: 5.3 years). A score $>25$ points on the dimension of vasomotor problems (or menopausal health), showed values of sensitivity and specificity $>80 \%$ for identifying women with vasomotor syndrome of a moderate-severe level that requires pharmacological treatment. Predictive validity for menopauserelated health outcomes was confirmed; a change of 6.7 points in the scale score, equivalent to the value of its minimal difference, is indicative of a significant increase in the degree of disability regarding work/day-to-day activities, greater economic loss due to decreased work productivity, fewer years of life expectancy without disability, fewer hours of undisturbed sleep, and more visits to the physician per year due to menopausal symptoms.

Conclusions: These results confirm the criterion and predictive validity of the Cervantes-SF scale in peri/postmenopausal women.

Keywords: Cervantes-SF, health-related quality of life, menopause, normative scales 
Abbreviations

\begin{tabular}{|l|l|}
\hline AUC & area under the curve \\
\hline Cervantes-SF & Cervantes scale sort form \\
\hline CI & Confidence Interval \\
\hline DALE & Disability-adjusted-life-expectancy \\
\hline EQ-5D-3L & Scale Grupo EuroQoL 5 dimensions \\
\hline EQ-VAS & EQ-5D-3L visual analog scale \\
\hline HRQoL & health-related quality of life \\
\hline INE & Instituto Nacional de Estadística Español \\
\hline LR & likelihood ratio \\
\hline MHT & menopausal hormone therapy \\
\hline MID & minimally important difference \\
\hline NPV & negative predictive value \\
\hline PPV & positive predictive value \\
\hline PRO & patient-reported health outcomes \\
\hline ROC & Receiver-Operating-Characteristic \\
\hline SEM & standard error of measurement \\
\hline SERMs & selective estrogen-receptor modulators \\
\hline WPAI-GH & $\begin{array}{l}\text { Work Productivity and Activity Impairment Questionnaire - } \\
\text { General Health }\end{array}$ \\
\hline
\end{tabular}




\section{1-Introduction}

Menopause is the result of the loss of ovarian follicular activity, and, although the age of onset varies considerably, it usually occurs around the age of 50-52 years ${ }^{1}$. During this period, women experience significant physical and psychological changes that impact their health-related quality of life (HRQoL) $)^{2,3}$. HRQoL assessment has become an essential component of studying the effects of menopause on well-being, as well as evaluating the benefits of hormonal treatments or any other therapy used at this stage of a woman's life ${ }^{4,5}$. The Cervantes scale is a self-administered, multidimensional questionnaire designed to measure HRQoL in peri- and post-menopausal women ${ }^{6}$. A 16-item shortened version (Cervantes-SF) is available, compared with 31 in the original version, which facilitates its use in daily clinical practice ${ }^{7}$ whilst retaining the original structure with four first-order dimensions and three second-order dimensions: Menopause and Health (Vasomotor Symptoms, Health and Aging), Psychology, Sexuality, and Partner Relationship, while showing good psychometric properties for its use in clinical settings ${ }^{9}$. This version has been shown to measure a health concept comparable to the original Cervantes scale ${ }^{7}$, whilst being more feasible to administer and score. Although the short version of the Cervantes scale has previously been shown to have good psychometric properties, rather less is known about its other attributes such as criterion or predictive validity.

Criterion validity is a property that indicates whether the new scale measures a concept similar to that measures by the original scale, while predictive validity informs us of the instrument's ability to explain or predict women's health outcomes that have not been directly measured, or that occur with a time delay $^{10-12}$. The criterion validity of the Cervantes-SF, if present, would allow the new scale to be used as a substitute for the existing instrument without losing information about the patient, whilst having the advantage of involving a lower administration load. Predictive validity would support the use of the scale in routine clinical practice, which would allow for estimating the deterioration of HRQoL resulting from menopausal symptomatology by measuring various health outcomes that are of interest for the clinician and the patient, and which could guide clinical decision making. Therefore, the aim of this study was to confirm the criterion validity of the scale for measuring menopausal symptomatology and its pharmacological treatment, and to confirm its predictive validity with regard to various health outcomes. 


\section{2-Methods}

\section{1-Study design}

This research took the form of a cross-sectional, observational, non-interventional study, following the STROBE initiative guidelines or checklist (See Supplementary Materials, https://www.strobestatement.org $)^{13}$.

\section{2-Population}

The data used to check the criterion and predictive validity of the Cervantes-SF scale were extracted from a psychometric validation study of the Cervantes-SF scale ${ }^{8}$. This study initially included 317 women, and this sample formed the basis for testing the factor structure of the scale and some of its psychometric properties. They were peri-menopausal or postmenopausal women according to STRAW ${ }^{14}$ criteria, who reported having their last menstrual period 12 or more months prior to study inclusion, and with an age range of 40 to 65 years. This study was conducted in gynecology outpatient clinics at 13 hospitals across seven different regions of Spain. Information was collected regarding climacteric symptomatology, sociodemographic data and clinical history, as well as the participants' responses to various measures of patient-reported health outcomes (PRO).

\section{3-Criterion validity test}

Criterion validity was tested by establishing the a priori hypothesis that the Cervantes-SF scale shows a significant relationship with the main clinical criteria used to evaluate the characteristic symptomatology of menopause $\mathrm{g}^{9-12}$. These criteria are the presence of vasomotor (vasomotor syndrome) and genital symptoms (genital syndrome) ${ }^{15}$, along with receiving treatment for this symptomatology and the type of treatment applied. The Menopause Symptom Severity Scale (see Supplementary Materials ${ }^{15-}$

${ }^{17}$ ) was used to group women with both vasomotor and genital syndrome into four categories: absent, mild, moderate, and severe. Once classified, we analyzed whether they were receiving pharmacological treatment, along with the type of drugs applied: specific treatments (menopausal hormone therapy [MHT], selective estrogen-receptor modulators [SERMs], isoflavones, black cohosh, etc.), non-specific treatments (antidepressants, anxiolytics, hypnotics, etc.), or both. 


\section{4-Predictive validity test}

A number of variables and the results of PROs included in the mentioned psychometric validation study were used (see Supplementary material for a description of the scales and questionnaires used $)^{8}$. The PROs included the Spanish versions of the EQ-5D-3L (Grupo EuroQoL) ${ }^{18}$ and the WPAI-General Health (WPAI-GH, Work Productivity and Activity Impairment Questionnaire - General Health) ${ }^{19}$. The variables used for evaluating predictive validity were the hours of undisturbed sleep each day (effective sleep hours $)^{20}$, and healthcare burden expressed as the monthly number of medical visits to family medicine and gynecology clinics due to menopausal symptoms, projected annually. The EQ-5D-3L instrument was used to calculate the utility or social value that society grants to the health status of the individual, a complementary value of which represents the value of disutility or disability. The value of disutility was used to estimate the years of life expectancy lost due to disability, which, subtracted from the current years of life expectancy according to the age of each participant, allows us to determine the DALE (Disability-adjusted-life-expectancy), expressed in years, which represents, for each participant, the time of healthy life expectancy without disability (see Supplementary material) ${ }^{21}$. The EQ-5D-3L is accompanied by a visual analog scale (EQ-VAS) that measures the patient's current self-assessed health status, the end values of which are 0 (worst imaginable health) and 100 (best imaginable health). The WPAI-GH questionnaire was used to measure the percentage of lost work productivity (absenteeism or presenteeism) and the percentage of impairment for performing daily life activities as a result of a health problem ${ }^{21}$. By multiplying the percentage of work disability by the average net annual labor cost (in this case the last one available corresponds to that of the year 2018 in Spain; average $=30,883.44 €$; INE, 2018) ${ }^{22}$, it was possible to estimate the economic loss per active person each year due to lost or decreased labor productivity.

\section{5-Statistical analysis}

Statistical analyses were conducted using the IBM SPSS package, Version 26.0, NY, USA, (https://www.ibm.com/analytics/spss-statistics-software). First, a descriptive analysis of the sociodemographic and clinical variables was conducted, along with climacteric symptomatology in 
those cases where this information was available. Criterion validity was initially analyzed by estimating the strength and statistical significance of the correlation between scores on the Cervantes-SF scale (total score and dimensions) and the intensity of vasomotor and genital syndromes, through the calculation of Pearson's $r$ and Spearman's rho coefficients (Table S1A and Table S1B, Supplementary material). Once the existence of a significant correlation was demonstrated, the women were grouped according to the intensity of the vasomotor and genital syndromes using a dichotomous criterion: absent/mild and moderate/severe in both cases. This classification criterion was chosen because it is the one that best categorizes women according to their need to receive pharmacological treatment for climacteric symptoms in the analyzed sample and therefore has greater practical utility from a clinical standpoint ${ }^{23}$. The percentages of women receiving treatment (any, specific, non-specific, or MHT only) for vasomotor and genital syndrome according to the above classification were calculated and logistic regression was used to estimate the odds ratio (with a confidence interval - CI- of 95\%) as a measure of the strength of the correlation. Once it had been confirmed that the probability of receiving treatment is significantly higher in women with moderate to severe vasomotor or genital syndrome, ROC (Receiver-OperatingCharacteristic) curve analysis was used to estimate the cut-off point in the Cervantes-SF scale total score, and in each of its dimensions, which best categorizes menopausal women according to the intensity of both vasomotor and genital syndromes. Youden's J index was used to select the optimal cutoff point, calculating the combination of sensitivity and specificity indicators for each possible cut-off point $^{24}$. The indicators positive predictive value (PPV); negative predictive value (NPV); positive and negative likelihood ratio (LR) were also calculated. The $\operatorname{LR}(+)$ indicates how likely it is to find a score higher than the proposed cut-off point for criterion validity in women with a moderate/severe vasomotor or genital syndrome than in those without; LR(-) indicates how likely it is to find a score lower than the proposed cut-off point for criterion validity in women with moderate/severe vasomotor or genital syndrome than in those without.

Predictive validity was assessed by predicting several health outcomes through multivariate linear regression analysis, whilst keeping the total score of the Cervantes-SF scale fixed as an explanatory variable, both in continuous form and clustered into normative percentiles. The stepwise elimination method was applied for the rest of the independent variables proposed in the models: age (years), body 
mass index $\left(\mathrm{kg} / \mathrm{m}^{2}\right)$, education level, marital status, menopausal status (peri or postmenopausal), age at menarche (years), number of comorbidities and their severity according to Charlson's 8-item abbreviated severity index (0-10 points) $)^{25}$, tobacco consumption (yes/no) and alcohol consumption (yes/no), and pharmacological treatment of climacteric syndrome (yes/no). The health outcomes used as a criterion (or dependent) variable to test the predictive validity of the Cervantes-SF were degree of impairment for performing work and daily activities (both expressed as a percentage) using the WPAIGH scale, economic loss per person-year due to decreased work productivity (euros, year 2018), current self-reported health status using the EQ-VAS, years of healthy life expectancy without disability, daily hours of undisturbed (effective) sleep, and the variation in the number of annual medical visits due to menopausal symptoms. From the estimated models, we calculated, for each health outcome, the minimally important difference (MID), which is equivalent to the smallest change (both increase and decrease) in the total Cervantes-SF scale score perceived by the menopausal woman when a change in health-related quality of life has occurred due to menopausal symptoms ${ }^{26-29}$. In the total score of the Cervantes-SF scale, the magnitude of the MID is equivalent to 1 time the standard error of measurement (SEM) which is of a magnitude equal to 6.7 points in the total score of the scale, as previously mentioned.

\section{3-Results}

The original sample consisted of 317 women with a mean age of 55.7 years ( $\mathrm{SD}=5.3$ years), while the effective sample size analyzed was reduced to 308 women, nine (2.8\%) of whom were excluded because they did not meet the selection criteria. Table 1 shows the main demographic descriptors. Most women (75.4\%) were in the post-menopausal stage, while $22.3 \%$ were in the perimenopausal stage. Of the sample, $78.7 \%$ were sexually active and had an average body mass index of $25.2 \mathrm{~kg} / \mathrm{m}^{2}\left(\mathrm{SD}=4.2 \mathrm{~kg} / \mathrm{m}^{2}\right)$, and $69 \%$ of the patients attended a consultation for their menopause check-up. A total of $25.6 \%$ of the patients were current smokers, with an average consumption of $10.3(\mathrm{SD}=5.5)$ cigarettes/day. Further, $25.2 \%$ of the patients consumed alcohol, with an average of $1.2(\mathrm{SD}=0.5)$ units/day. No other toxic habits were mentioned. 
The percentages of women receiving pharmacological treatment for the presence of a vasomotor or genital syndrome (moderate or severe) are displayed in Figure 1 A and 1 B, respectively. Women with moderate or severe vasomotor syndrome were between 2.3 and 3 times more likely to be undergoing pharmacological treatment (any treatment for menopause, either specific to climacteric symptomatology, including MHT, or non-specific) compared with those without moderate or severe syndrome. In the case of genital syndrome, this significantly higher probability was only observed for the set of all treatments (any treatment) and for specific treatments (Figure 1B). Table 2 and Figure 2 show the results of the ROC curve analysis for the various diagnostic test indicators, to test the criterion validity in the case of vasomotor syndrome. The cut-off point for both the total score of the scale and its dimensions (which optimizes the indicators of sensitivity and specificity according to Youden's J index) is 25 points or more for moderate or severe vasomotor syndrome, particularly for vasomotor and menopausal dimensions and health, with values of the area under the curve (AUC) $>0.8$, diagnostic indicators close to or above $80 \%$ and diagnostic odds $>10$. These results indicate that there is a greater likelihood of finding a woman with a score $>25$ when the vasomotor syndrome is moderate or severe than when it is absent or mild and, therefore the probability of being under pharmacological treatment for menopausal symptoms is at least double or triple. Table S2 (Supplementary material) includes the coordinates of the ROC curve analysis for the total score and the dimensions of the Cervantes-SF scale for the moderate or severe vasomotor syndrome criterion. The criterion validity of the Cervantes-SF scale for moderate to severe genital syndrome did not show a cut-off point that optimized the diagnostic indicators in an acceptable way (Figure S2, Supplementary material).

Table 3 shows the predictive validity of the Cervantes-SF total score for health outcomes related to the degree of impairment in performing work and general daily activities, economic loss due to decreased work productivity, years of life expectancy without disability (DALE), generic health status, hours of undisturbed sleep, and annual number of additional medical visits related to menopausal symptoms. This table also shows the magnitude of the MID in those results in the event that the total score on the Cervantes-SF scale had a variation equal to or greater than a MID value of 6.7 points. Table 4 also shows the predictive validity of the Cervantes-SF total score for the above health outcome measures using the normative percentile values of the total score on the scale. This makes it possible to interpret the change 
that occurs in the health outcome when the total score of the scale changes from one percentile interval to another, either spontaneously or as the result of a health intervention.

\section{4-Discussion}

The Cervantes-SF scale has been shown to have good psychometric properties for measuring HRQoL in women with menopausal symptoms ${ }^{8}$, and, under conditions of routine medical practice it has been shown that women who choose menopausal hormone therapy for the treatment of menopausal symptoms have a poorer quality of life according to this scale ${ }^{30}$. However, until now, no tests have been conducted to confirm whether this instrument has the attributes that any perceived health instrument should have available to facilitate the interpretation of the health status of the population and patients ${ }^{9,10}$, specifically, criterion validity and predictive validity. In this work, and to complement the measurement of its main psychometric properties, these two attributes have been analyzed. To test predictive validity, we used the variation of the scale score by a magnitude equal to or greater than 1 SEM, which is 6.7 points 9 . The SEM is considered a good indicator of the MID of any instrument and is interpreted as the difference that is perceived by the patient when a change in their health has occurred that is detectable by the subject themselves and, therefore, relevant ${ }^{26-30}$. That is, a variation (both increase and decrease) in the Cervantes-SF scale score of 6.7 or more points would be due to a change in the woman's HRQoL in the peri/postmenopausal period that would be perceived by the woman herself as indicating that she has experienced a change in her health status. Therefore, this could help to inform the decision making of the clinician responsible for the care of the patient ${ }^{26,30}$. In this study, it has been shown that a change of this magnitude predicts a minimally relevant change in the degree of impairment in work and general daily activities, economic impact due to decreased work productivity, variation in the number of years of life expectancy without disability, change in generic health status, number of daily hours of undisturbed sleep, and annual number of medical visits related to menopausal symptoms. These data can facilitate interpretation of the scale score if used routinely in clinical practice. In fact, the predictive validity for the mentioned health outcomes was confirmed not only by using the continuous total score of the scale, but also by using the percentiles, once the woman had been located in relation to her reference population. 
Moreover, we have confirmed the criterion validity of the scale for identifying women with moderate to severe vasomotor syndrome, but not for genital syndrome. The observed cut-off point, $>25$ points in the dimensions of menopause and health or in the subdimension of vasomotor problems $(65 \%$ and $59 \%$ of the women in the sample showed this score, respectively), has a sensitivity and specificity of approximately $80 \%$ or higher and a diagnostic odds ratio of more than 10 for detecting a moderate or severe vasomotor syndrome. In our work, women with moderate to severe vasomotor syndrome were shown to have a probability of being on pharmacological treatment (mainly MHT) that was between two and three times that in relation to women for whom the severity of the syndrome is absent or mild, which supports the ability of the scale to identify women who require MHT when they present menopause symptoms associated with a poor quality of life, as previously shown in conditions of routine clinical practice ${ }^{30}$. Thus, to illustrate, a hypothetical woman aged 55 years, active at work and in her menopause, who had a total score on the Cervantes-SF scale of 60 points, and 30 points on the vasomotor dimension, would have a probability of more than $83 \%$ of having a moderate or severe vasomotor syndrome that requires pharmacological treatment, which is two and three times more likely than the case in which the vasomotor syndrome was absent or mild. Given that this woman is placed above the 90th percentile of the total score relative to her reference population according to the Cervantes-SF scale population norms, if a health intervention were not prescribed to improve her relative position, and her HRQoL was maintained at that score, this would have a negative impact on various health outcomes. This impact would be equivalent to a $20 \%$ work impairment with an economic impact due to loss of work productivity of 6,066 euros per year, $42 \%$ impairment in carrying out general daily activities, a $31 \%$ deterioration in general health status, a loss of 9.7 years of life expectancy without disability, a loss of 4.7 hours of undisturbed sleep per day and a 0.5 increase in the annual number of medical visits (family medical or gynecology clinics).

The scientific literature indicates the existence of other scales or instruments for measuring the impact of peri/postmenopausal symptoms on women's HRQoL ${ }^{31}$. For this purpose, another scale, originally developed in Spanish, the Menopause and Quality of Life Scale (MENCAV) ${ }^{32}$ is available whilst other menopause-related scales have been developed in the international context, such as the Menopause Specific Quality of Life Questionnaire (MENQOL) ${ }^{33}$, the Greene Climacteric Scale ${ }^{34}$, Woman's Health 
Questionnaire (WHQ) ${ }^{35}$, or the Menopause Rating Scale (MRS) ${ }^{36}$. And whilst some of these instruments have been adapted to Spanish, none of them have been confirmed to show the criterion or predictive validity attributes evaluated in our research. Therefore, we believe that, in terms of utility and interpretability, the findings of the present study provide further support for the value of using the Cervantes-SF scale in comparison with other existing instruments.

This work is not exempt from limitations. One possible limitation is that the sample used comes from daily clinical practice (real-world) and although representative from a clinical point of view, we cannot rule out the potential introduction of selection bias that could have interfered with the composition of the sample in terms of age, socioeconomic level, and education. Further, it will be necessary to confirm the predictive validity results in future studies by administering the Cervantes-SF scale and measuring the health outcomes analyzed in this work in a sample of menopausal women that is representative in terms of age, socioeconomic, educational and cultural variables. Finally, although the scale has criterion validity for moderate or severe vasomotor syndrome, it has not been possible to confirm this attribute for the genital syndrome.

In conclusion, and in spite of these potential limitations, the results presented support both the predictive validity of health outcomes in various aspects of women's daily life during menopause, and the criterion validity of the Cervantes-SF scale for identifying women with moderate to severe vasomotor syndrome requiring pharmacological treatment.

\section{Author contributions}

All authors had complete access to the data, participated in the analysis and/or interpretation of results, and drafted the manuscript. PJC, MF, LB, NM, PL and JR were responsible for the design of the study. Data analyses were conducted by MM and MAR. All authors have seen and approved the final version.

\section{Acknowledgments}

The authors wish to thank the Spanish Menopause Society for its support and guidance. 


\section{References}

1. Mendoza N, Juliá MD, Galliano D, Coronado P, Díaz B, Fontes J, et al. Spanish consensus on premature menopause. Maturitas. 2015; 80(2):220-5.

2. Vélez Toral M, Godoy-Izquierdo D, Padial García A, Lara Moreno R, Mendoza Ladrón de Guevara N, Salamanca Ballesteros A, et al. Psychosocial interventions in perimenopausal and postmenopausal women: a systematic review of randomised and non-randomised trials and noncontrolled studies. Maturitas. 2014; 77(2):93-110.

3. Avis NE, Stellato R, Crawford S, Bromberger J, Ganz P, Cain V, et al. Is there a menopausal syndrome? Menopausal status and symptoms across racial/ethnic groups. Soc Science Med 2001;52:345-56.

4. Meeuwsen IB, Samson MM, Duursma SA, Verhaar HJ. The influence of tibolone on quality of life in postmenopausal women. Maturitas 2002;41:35-43. Mendoza N, Abad P, Baró F, Cancelo MJ, Llaneza P, Manubens M, Quereda F, Sánchez-Borrego R. Spanish Menopause Society position statement: use of tibolone in postmenopausal women. Menopause. 2013; 20(7):754-60.

5. Palacios S, Ferrer-Barriendos J, Parrilla JJ, Castelo-Branco C, Manubens M, Alberich X, et al. Calidad de vida relacionada con la salud en la mujer española durante la perimenopausia y posmenopausia. Desarrollo y validación de la Escala Cervantes. Med Clin (Barc) 2004; 122: 205-11.

6. Coronado P, Sánchez Borrego R, Palacios S, Ruiz MA, Rejas J. Structural validity of a 16-item abridged version of the Cervantes health-related quality of life scale for menopause: the Cervantes Short-Form scale. Menopause 2015; 22: 325-36.

7. Coronado PJ, Sánchez-Borrego R, Ruiz MA, Baquedano L, Sánchez S, Argudo C, et al. Psychometric attributes of the Cervantes short-form questionnaire for measuring health-related quality of life in menopausal women. Maturitas. 2016; 84:55-62.

8. Aaronson N, Alonso J, Burnam A, et al. Assessing health status and quality-of-life instruments: attributes and review criteria. Qual Life Res 2002; 11: 193-205.

9. Chassany O, Sagnier P, Marquis P, Fullerton S, Aaronson N for the European Regulatory Issues on Quality of Life Assessment Group. Patient-reported outcomes: the example of health-related quality 
of life - A European guidance document for the improved integration of health-related quality of life assessment in the drug regulatory process. Drug Information Journal 2002; 36: 209-38.

10. Nunnally JC, Bernstein IH. Psychometric theory. 3rd ed. New York: McGraw-Hill, 1994.

11. Fayers PM, Machin D. Quality of life: The assessment, analysis and interpretation of patientreported outcomes. Second edition. Chichester, UK: John Wiley and Sons, Ltd; 2007:1-10.

12. STROBE Statement. Home. https://strobe-statement.org/index.php?id=strobe-home. Acceso Junio 2020.

13. Harlow SD, Gass M, Hall JE, Lobo R, Maki P, Rebar RW, Sherman S, Sluss PM, de Villiers TJ., STRAW +10 Collaborative Group. Executive summary of the Stages of Reproductive Aging Workshop + 10: addressing the unfinished agenda of staging reproductive aging. Fertil Steril 2012; 97(4):843-51.

14. ACOG Practice Bulletin No. 141: management of menopausal symptoms. Obstet Gynecol. 2014; 123(1):202-16. PMID: 24463691 www.ncbi.nlm.nih.gov/pubmed/24463691. (Acceso 20 de abril de 2020).

15. Whiteley J, Wagner JS, Bushmakin A, Kopenhafer L, DiBonaventura M, Racketa J. Impact of the severity of vasomotor symptoms on health status, resource use and productivity. Menopause 2013; $20: 518-24$

16. Centers for Disease Control and Prevention (CDC) NHANES 2009-2010. National Center for Health Statistics (NCHS). http://wwwn.cdc.gov/nchs/nhanes/search/nhanes09_10.aspx. (Acceso 9 de octubre 2013).

17. The EuroQol Group. EuroQol - a new facility for the measurement of health-related quality of life. Health Policy 1990; 16:199-208.

18. Zbrozek AS, Dukes EM. The validity and reproducibility of a work productivity and activity impairment instrument. Pharmacoeconomics 1993; 4:353-65.

19. Kim MJ, Yim G, Park HY. Vasomotor and physical menopausal symptoms are associated with sleep quality. PLoS One. 2018; 13(2): e0192934. 
20. Mathers CD, Sadana R, Salomon JA, Murray CJL, Lopez AD. Estimates of DALE for 191 countries: methods and results. Global Programme on Evidence for Health Policy Working Paper No. 16. World Health Organization June 2000.

21. INE, 2018. Encuesta de costes laborales. Disponible en: https://www.ine.es/dyngs/INEbase/es/operacion.htm?c=Estadistica_C\&cid=1254736060920\&me nu=ultiDatos\&idp=1254735976596 (Acceso 20 de abril de 2020).

22. Mendoza N, Sánchez-Borrego R, Cancelo MJ, Calvo A, Checa MA, Cortés J, et al. Position of the Spanish Menopause Society regarding the management of perimenopause. Maturitas 2013; 74(3):283-90.

23. Schisterman EF, Perkins NJ, Liu A, Bondell H. Optimal cut-point and its corresponding Youden Index to discriminate individuals using pooled blood samples. Epidemiology 2005; 16: 73-81.

24. Berkman LF, Leo-Summers L, Horwitz RI. Emotional support and survival after myocardial infarction. A prospective, population-based study of the elderly. Ann Intern Med 1992; 117: 1003-9.

25. Guyat GH, Osoba D, Wu AW, Wyrwich KW, Norman GR, and the clinical significance consensus meeting group. Methods to explain the clinical significance of Health Status Measures. Mayo Clinic Proc 2002; 77: 371-83.

26. Revicki D, Hays RD, Cella D, Sloan J. Recommended methods for determining responsiveness and minimally important differences for patient-reported outcomes. J Clin Epidemiol. 2008; 61: 102-9.

27. Rejas J, Pardo A, Ruiz MA. Standard error of measurement as a valid alternative to minimally important difference for evaluating the magnitude of changes in patient-reported outcomes measures. J Clin Epidemiol. 2008; 61(4):350-6.

28. Wyrwich KW, Tierney WM, Wolinsky FD. Further evidence supporting an SEM-based criterion for identifying meaningful intra-individual changes in health-related quality of life. J Clin Epidemiol. 1999; 52: 861-73.

29. Fasero M, Hernández A, Varillas-Delgado D, Coronado PJ. Women with low quality of life by Cervantes-short form scale choose menopausal hormone therapy. Eur J Obstet Gynecol Reprod Biol 2020; 252: 43-49. 
30. Jenabil E, Shobeiri1 F, Hazavehei SMM, Roshanaei G. Assessment of Questionnaire Measuring Quality of Life in Menopausal Women: A Systematic Review. Oman Medical Journal 2015; 30 (3): 151-6.

31. Buendía A, Bermejo J, Rodríguez Segarra R, Yubero Bascuñana N, Martínez Vizcaíno V. Diseño y validación de un cuestionario en castellano para medir la calidad de vida en mujeres posmenopáusicas: el cuestionario MENCAV. Aten Primaria 2001; 27:94-100.

32. Hilditch JR, Lewis J, Peter A, van Maris B, Ross A, Franssen E, et al. A menopause-specific quality of life questionnaire: development and psychometric properties. Maturitas. 1996; 24(3):161-75.

33. Greene JG. Constructing a standard climacteric scale. Maturitas 2008; 61 (1-2): 78-84.

34. Hunter MS. The Women's Health Questionnaire (WHQ): frequently asked questions (FAQ). Health Qual Life Outcomes 2003; 1(1):41.

35. Hauser GA, Huber IC, Keller PJ, Lauritzen C, Schneider HPG. Evaluation der klinischen Beschwerden (Menopause Rating Scale) Zentralbl Gynakol. 1994; 116:16-23. 


\section{Figure legends}

Figure 1. Patients receiving menopausal pharmacological therapy according with the presence of a moderate-to-severe menopausal vasomotor syndrome (graph A) or genital syndrome (graph B).

Figure 2. Criterion validity of the Abbreviated Scale Cervantes-SF (total score and dimensions) for the criterion presence of moderate-to-severe menopausal vasomotor syndrome. 
Table 1. Demographic and clinical data of the women included in the study of psychometric validity of the Cervantes-SF scale.

\begin{tabular}{|c|c|}
\hline Age (years): Mean (SD) & $55.7(5.3)$ \\
\hline BMI $\left(\mathrm{kg} / \mathrm{m}^{2}\right)$ : Mean (SD) & $25.2(4.2)$ \\
\hline \multicolumn{2}{|l|}{ Menopausal stage (\%) } \\
\hline Post-menopausal & $232(75.4 \%)$ \\
\hline Peri-menopausal & $69(22.3 \%)$ \\
\hline Sexually active: (\%) & $235(78.7 \%)$ \\
\hline Attending menopause consultation: $(\%)$ & $213(69.0 \%)$ \\
\hline \multicolumn{2}{|l|}{ Climacteric symptoms: $(\%)$} \\
\hline Suffocation & $228(73.8 \%)$ \\
\hline Decrease in sexual drive & $222(71.8 \%)$ \\
\hline Vaginal dryness & $217(70.2 \%)$ \\
\hline Sweating & $202(65.4 \%)$ \\
\hline Dyspareunia & $150(48.5 \%)$ \\
\hline Tremors & $92(29.8 \%)$ \\
\hline Irritability & $12(3.9 \%)$ \\
\hline Dysthymia & $8(2.6 \%)$ \\
\hline Insomnia & $7(2.3 \%)$ \\
\hline Asthenia & $6(1.9 \%)$ \\
\hline Changes in mood & $6(1.9 \%)$ \\
\hline Joint pain & $6(1.9 \%)$ \\
\hline Nervousness & $5(1.6 \%)$ \\
\hline None & $27(9 \%)$ \\
\hline \multicolumn{2}{|l|}{ Educational Level (\%) } \\
\hline None & $0(0 \%)$ \\
\hline Primary & $56(18 \%)$ \\
\hline Secondary & $108(35 \%)$ \\
\hline Professional degree & $1(0.3 \%)$ \\
\hline Higher & $142(17 \%)$ \\
\hline \multicolumn{2}{|l|}{ Employment status (\%) } \\
\hline Active & $216(70 \%)$ \\
\hline Disabled & $4(1 \%)$ \\
\hline Unemployed & $16(5 \%)$ \\
\hline Retired & $11(4 \%)$ \\
\hline Homemaker & $57(19 \%)$ \\
\hline \multicolumn{2}{|l|}{ Civil status (\%) } \\
\hline Single & $25(8 \%)$ \\
\hline Married & $221(72 \%)$ \\
\hline Divorced & $42(14 \%)$ \\
\hline Widowed & $18(6 \%)$ \\
\hline Other & $2(1 \%)$ \\
\hline Smoker (\%) & $78(25.6 \%)$ \\
\hline Cigarettes (units/day): Mean (SD) & $10.3(5.5)$ \\
\hline Alcohol consumption (\%) & $77(25.2 \%)$ \\
\hline Units/day: Mean (SD) & $1.2(0.5)$ \\
\hline
\end{tabular}


Table 2. Criterion validity of the abridged Cervantes-SF scale for the presence of moderate or severe vasomotor s the total score and dimensions.

\begin{tabular}{lccccccccc}
\hline \multicolumn{1}{c}{ Dimension } & $\begin{array}{c}\text { Area under } \\
\text { the curve } \\
\text { (AUC) }\end{array}$ & $\begin{array}{c}\text { Standar } \\
\mathbf{d} \text { error }\end{array}$ & $\mathbf{p}$ & Sensitivity & Specificity & PPV & NPV & $\begin{array}{c}\text { Youden,s } \\
\text { J statistic }\end{array}$ & Di \\
\hline Total Score & 0.798 & 0.026 & $<0.001$ & $79.2 \%$ & $63.8 \%$ & $68.6 \%$ & $75.4 \%$ & 0.415 & \\
\hline Menopause and health & 0.883 & 0.020 & $<0.001$ & $81.9 \%$ & $77.9 \%$ & $78.7 \%$ & $81.1 \%$ & 0.588 & 1 \\
$\quad$ Vasomotor & 0.923 & 0.017 & $<0.001$ & $89.9 \%$ & $81.9 \%$ & $83.2 \%$ & $89.1 \%$ & 0.711 & 40 \\
$\quad$ Health & 0.720 & 0.030 & $<0.001$ & $58.4 \%$ & $71.8 \%$ & $67.4 \%$ & $63.3 \%$ & 0.307 \\
$\quad$ Aging & 0.693 & 0.032 & $<0.001$ & $61.1 \%$ & $67.1 \%$ & $65.0 \%$ & $63.3 \%$ & 0.286 \\
Sexuality & 0.567 & 0.035 & 0.053 & $75.5 \%$ & $37.5 \%$ & $55.2 \%$ & $60.0 \%$ & 0.125 \\
Partner Relationship & 0.556 & 0.035 & 0.108 & $39.6 \%$ & $67.4 \%$ & $55.0 \%$ & $52.5 \%$ & 0.077 \\
Psychological & 0.698 & 0.031 & $<0.001$ & $51.7 \%$ & $71.1 \%$ & $64.2 \%$ & $59.6 \%$ & 0.249 \\
\hline
\end{tabular}

PPV= Positive Predictive Value; NPV= Negative Predictive Value; LR $(+)$ : Likelihood ratio of a positive test (indicates how likely it is to find a scor in women with a moderate/severe vasomotor or genital syndrome than in those without); LR(-): Likelihood ratio of a negative test (indicates how point for criterion validity in women with moderate/severe vasomotor or genital syndrome than in those without). 
Table 3. Predictive validity of the total score of the Cervantes-SF abbreviated scale according to different health ou

\begin{tabular}{|c|c|c|c|c|c|}
\hline Health Outcomes & $\begin{array}{c}\beta \text { Coefficient }{ }^{1} \\
\text { (Standard } \\
\text { error) }\end{array}$ & $\begin{array}{l}95 \% \text { CI of the } \beta \\
\text { coefficient }\end{array}$ & $\mathbf{p}$ & $\mathbf{R}^{2}$ adjusted & $\begin{array}{l}\text { Durbin- } \\
\text { Watson }\end{array}$ \\
\hline Impairment in work activity, $\%$ (WPAI-GH) & $0.295(0.078)$ & $0.141 ; 0.449$ & $<0.001$ & 0.106 & 2.05 \\
\hline $\begin{array}{l}\text { Economic loss per person per year due to } \\
\text { decreased work productivity } \quad(€ \text {,year 2018) }\end{array}$ & $91.0(24.1)$ & $43.5 ; 138.5$ & $<0.001$ & 0.106 & 2.05 \\
\hline $\begin{array}{l}\text { General impairments in carrying out daily living } \\
\text { activities, \% (WPAI-GH) }\end{array}$ & $0.619(0.075)$ & $0.470 ; 0.767$ & $<0.001$ & 0.230 & 1.54 \\
\hline $\begin{array}{l}\text { Generic Quality of Life, EVA points EQ-5D-3L } \\
\text { (range: } 0-100 \text { ) }\end{array}$ & $-0.457(0.058)$ & $-0.571 ;-0.334$ & $<0.001$ & 0.215 & 1.87 \\
\hline $\begin{array}{l}\text { Years of healthy life expectancy without } \\
\text { disability (DALE) })^{4} \text {, years }\end{array}$ & $-0.125(0.023)$ & $-0.171 ;-0.079$ & $<0.001$ & 0.376 & 1.85 \\
\hline $\begin{array}{l}\text { Effective daily sleep hours (without } \\
\text { interruption) }\end{array}$ & $-0.069(0.008)$ & $-0.085 ;-0.052$ & $<0.001$ & 0.258 & 1.89 \\
\hline $\begin{array}{l}\text { Variation in annual medical visits due to } \\
\text { menopausal symptoms }\end{array}$ & $0.008(0.002)$ & $0.004 ; 0.012$ & $<0.001$ & 0.103 & 1.99 \\
\hline
\end{tabular}

${ }^{1} \beta$ Coefficient estimated for the total score of the scale in continuous range 0-100 by means of multiple linear regression models using stepwis of the independent variables included in the regression models). ${ }^{2}$ Minimal change is equivalent to the change in health outcome when the minima SF scale total score perceived by the menopausal woman as a change in health-related quality of life resulting from menopausal symptoms. In $t$ of the minimally important difference (MID) is equivalent to 1 time the standard error of measurement (SEM) which is of magnitude equal to $10) ;{ }^{3}$ Calculated as the product of the $\%$ of impairment/loss of work activity due to menopausal symptoms multiplied by the average labor cost $\mathrm{f}$ (30.883,44€, Source: INE, 2018); ${ }^{4}$ DALE=Disability-adjusted-life-expectancy or years of healthy life expectancy without disability (see Metho of undisturbed daily sleep (see methods section for an explanation of its calculation); WPAI-GH=Work Productivity and Activity Impairment Q of work productivity/daily life activities] to $100 \%$ [complete loss of work productivity/daily life activities]; VAS=Visual Analog Scale or he questionnaire, ranging from 0 [worst imaginable health] to 100 [perfect health]. 
Table 4. Predictive validity of the total score of the Cervantes-SF scale according to different health outcomes expre of the scale.

\begin{tabular}{|c|c|c|c|c|}
\hline Health Outcomes & $\begin{array}{c}\beta \text { Coefficient }{ }^{1} \\
\text { (Standard } \\
\text { error) }\end{array}$ & $\begin{array}{l}95 \% \text { CI of the } \beta \\
\text { coefficient }\end{array}$ & $\mathbf{p}$ & $\mathbf{R}^{2}$ adjusted \\
\hline Impairments in work activity, \% (WPAI-GH) & $3.28(0.99)$ & $1.33 ; 5.22$ & 0.001 & 0.096 \\
\hline $\begin{array}{l}\text { Economic loss per person per year due to decreased work } \\
\text { productivity }(€ \text {, year } 2018)^{2}\end{array}$ & $1.011(304)$ & $411 ; 1612$ & 0.001 & 0.096 \\
\hline $\begin{array}{l}\text { Overall impairment in carrying out daily living activities, \% } \\
\text { (WPAI-GH) }\end{array}$ & $7.00(0.94)$ & $5.14 ; 8.86$ & $<0.001$ & 0.208 \\
\hline $\begin{array}{l}\text { Generic Quality of Life, EVA points EQ-5D-3L (range: 0- } \\
\text { 100) }\end{array}$ & $-5.14(0.66)$ & $-6.45 ;-3.83$ & $<0.001$ & 0.233 \\
\hline $\begin{array}{l}\text { Years of healthy life expectancy without disability } \\
\text { (DALE) })^{3} \text {, years }\end{array}$ & $-1.62(0.23)$ & $-2.08 ;-1.17$ & $<0.001$ & 0.539 \\
\hline Effective daily sleep hours (without interruption) ${ }^{4}$ & $-0.78(0.10)$ & $-0.97 ;-0.59$ & $<0.001$ & 0.252 \\
\hline $\begin{array}{l}\text { Variation in annual medical visits due to menopausal } \\
\text { symptoms }\end{array}$ & $0.09(0.02)$ & $0.05 ; 0.14$ & $<0.001$ & 0.106 \\
\hline
\end{tabular}

\footnotetext{
$1 \beta$ Coefficient estimated for the total score of the scale in the continuous range $0-100$ by means of multiple linear regression models using stepv for a description of the independent variables included in the regression models): $<\mathrm{P} 10=1 ; \mathrm{P} 10-<\mathrm{P} 25=2 ; \mathrm{P} 25-<\mathrm{P} 50=3 ; \mathrm{P} 50-<\mathrm{P} 75=4 ; \mathrm{P} 75-<\mathrm{P} 9$ the \% impairment/loss of work activity due to menopausal symptoms multiplied by the average labor cost for 2018 in Spain according to the IN 2018); ${ }^{3}$ DALE=Disability-adjusted-life-expectancy or years of healthy life expectancy without disability (see Methods section for explanation $\mathrm{c}$ interruption (see Methods section for an explanation of its calculation); WPAI-GH=Work Productivity and Activity Impairment Questionnai productivity/daily life activities] to $100 \%$ [complete loss of work productivity/daily life activities]; VAS=Visual Analog Scale or health the questionnaire, ranging from 0 [worst imaginable health] to 100 [perfect health].
} 


\section{Figure 1}
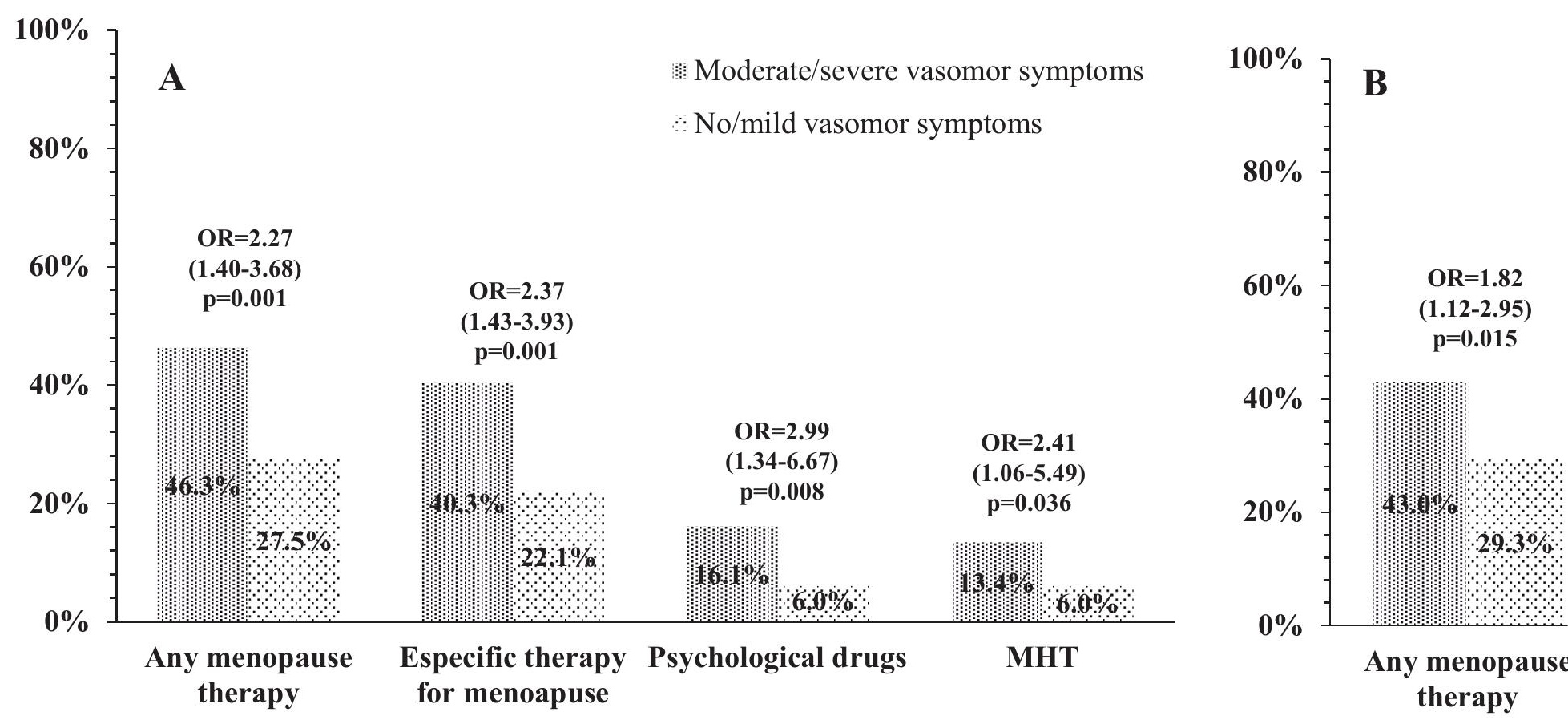
Figure 2

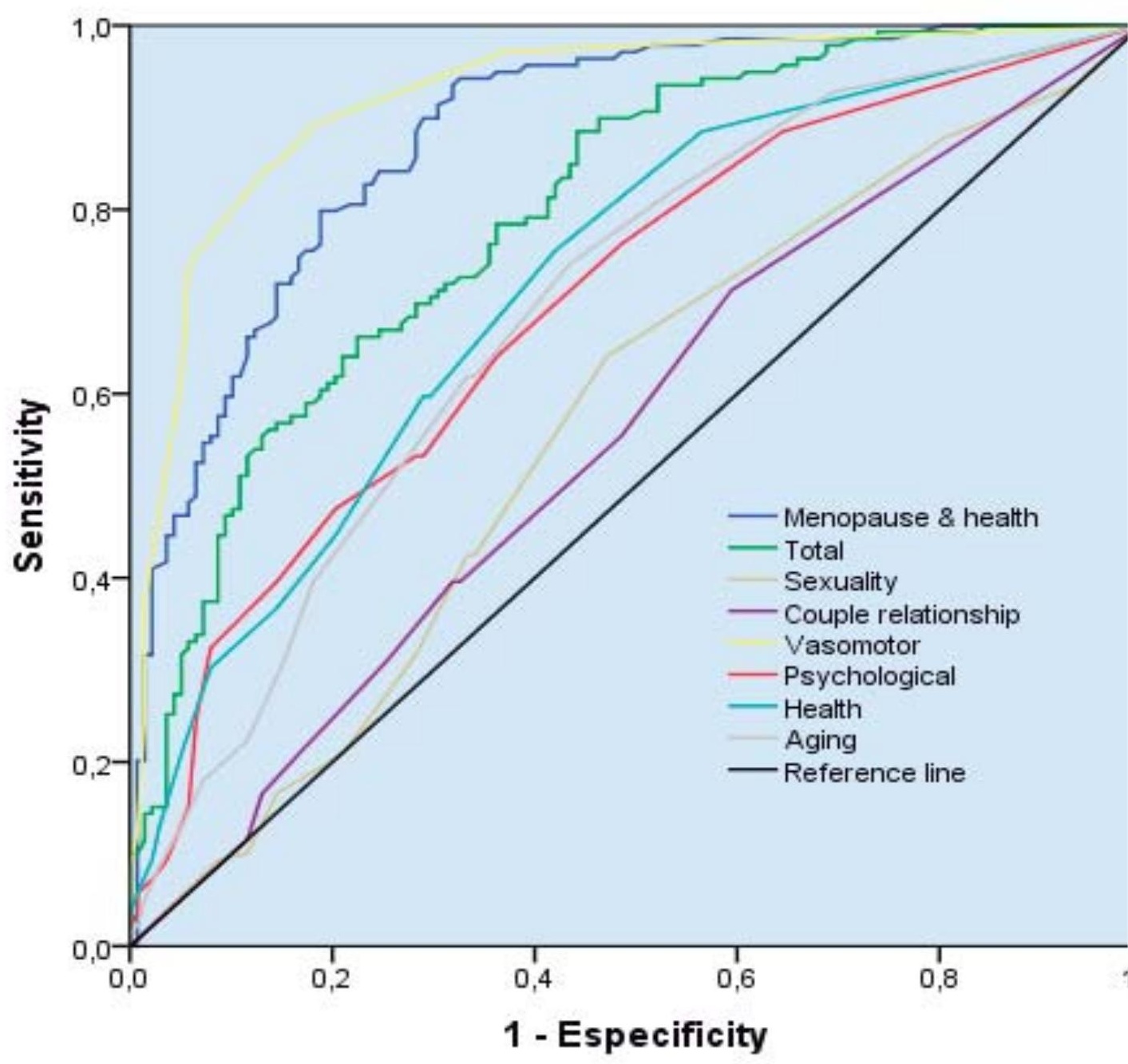


Click here to access/download Supplemental Data File (.doc, .tif, pdf, etc.) Criterion validity C-SF_Suppl material English.docx 